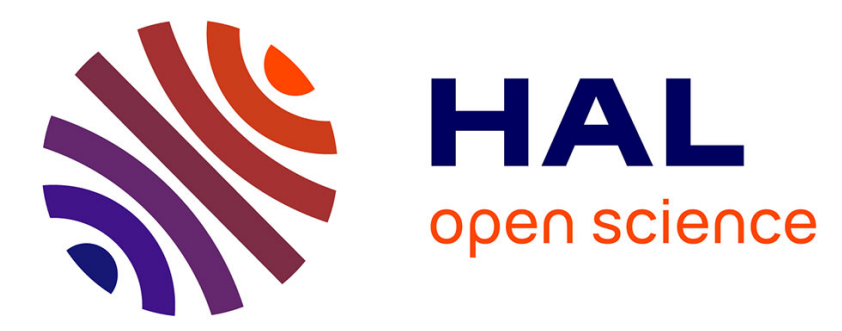

\title{
Unraveling Ultrafast Dynamics of the Photoswitchable Bridged Dithienylethenes Under Structural Constraints
}

Ismaïl Hamdi, Guy Buntinx, Olivier Poizat, Stéphanie Delbaere, Aurelie

Perrier, Rikiya Yamashita, Ken-Ichi Muraoka, Michinori Takeshita, Stephane

Aloise

\section{To cite this version:}

Ismaïl Hamdi, Guy Buntinx, Olivier Poizat, Stéphanie Delbaere, Aurelie Perrier, et al.. Unraveling Ultrafast Dynamics of the Photoswitchable Bridged Dithienylethenes Under Structural Constraints. Physical Chemistry Chemical Physics, 2019, 21 (12), pp.6407-6414. 10.1039/c8cp07100d . hal03036829

\section{HAL Id: hal-03036829 \\ https://hal.science/hal-03036829}

Submitted on 2 Dec 2020

HAL is a multi-disciplinary open access archive for the deposit and dissemination of scientific research documents, whether they are published or not. The documents may come from teaching and research institutions in France or abroad, or from public or private research centers.
L'archive ouverte pluridisciplinaire HAL, est destinée au dépôt et à la diffusion de documents scientifiques de niveau recherche, publiés ou non, émanant des établissements d'enseignement et de recherche français ou étrangers, des laboratoires publics ou privés. 


\title{
Unraveling Ultrafast Dynamics of the Photoswitchable Bridged Dithienylethenes Under Structural Constraints
}

\author{
Ismail Hamdi, ${ }^{* a}$ Guy Buntinx, ${ }^{a}$ Olivier Poizat, ${ }^{a}$ Stéphanie Delbaere, ${ }^{a}$ Aurélie Perrier,,${ }^{b, c}$ \\ Yamashita Rikiya, ${ }^{\mathrm{d}}$ Muraoka Ken-ichi, ${ }^{\mathrm{d}}$ Michinori Takeshita, ${ }^{\mathrm{d}}$ and Stéphane Aloïse*a
}

\begin{abstract}
Excited state dynamics of constrained photochromic benzodithienylethenes were adressed by considering the bridging with polyether chains (from $x=4$ to 6 units) at the ortho and meta positions of the aryl group, noticed DTE- $0_{x}$ and DTE- $m_{x}$, through time-resolved absorption spectroscopy supported with (TD)-DFT calculations. The photochromic parameters and geometrical structures of these series are discussed. A Novel photocyclization pathway via triplet state evidenced recently (Hamdi et al., Phys. Chem. Chem. Phys. 2016, 18, 28091-28100.) is largely dependent on the length and the position of the polyether chain. For the first time, by comparing the two series, we revealed, for the DTE-ox series, an interconversion not only in the ground state but also between the triplet states of the anti-parallel and parallel open form conformers.
\end{abstract}

\section{INTRODUCTION}

During the last few decades, diarylethenes (DAEs), for which photochromism is due to the reversible photoinduced transformation between an open form (OF) and a closed form (CF), have become one of the most important organic photoswitches used in various hot topic fields: DAEs are used to modulate fluorophore features, ${ }^{1}$ magnetic properties, ${ }^{2}$ electrochemical properties, ${ }^{3}$ metallic ion complexation ${ }^{4}$ for examples. More recently, DAEs have been used to obtain shape light sensitive crystals $^{5}$ or photoresponsive supramolecular assemblies. ${ }^{6}$ Exhaustive list of fundamental or industrial applications related to DAEs are covered by excellent books. ${ }^{7}$ Among DAEs, dithienylethenes (DTEs) belong to the most used photochromic compounds because of their high fatigue-resistant property and the thermal stability of both CF and OF isomers. ${ }^{8}$ Upon UV irradiation, DTEs undergo efficient photocyclization $\left(\phi_{c y c l} \sim 0.2-0.5\right)$ and less efficient photoreversion reactions $\left(\phi_{\text {rev }} \sim 0.01\right) .^{9}$ For photocyclization reactions, the quantum yield was thought to be limited to 0.5 explained by the coexistence, in equal proportions, of two isomers presenting either a parallel (P) or an anti-parallel (AP) conformation,

\footnotetext{
a. Univ.Lille, CNRS, UMR 8516, LASIR, Laboratoire de Spectrochimie Infrarouge et Raman, F59 000 Lille, France.

b. Université Paris Diderot, Sorbonne Paris Cité, 5 rue Thomas Mann, 75205 Paris Cedex 13, France.

c. Chimie Paris Tech, PSL Research University, CNRS, Institut de Recherche de Chimie Paris (IRCP), F-75005 Paris, France.

d. Department of Chemistry and Applied Chemistry, Faculty of Science and Engineering, Saga University, Honjo 1, Saga 840-8502, Japan.

* Corresponding authors1: stephane.aloise@univ-lille.fr

* Corresponding authors2: hamdiismailfsb@gmail.com

Electronic Supplementary Information (ESI) available: additional stationary

transition spectra; and DFT calculations.
}

only the latter being photoactive. ${ }^{8-10}$ Overcoming this inherent limitation was the focus of various research projects relying on a purposed designed synthetic approach ${ }^{11}$ or specific excited state reactivity. ${ }^{12}$ As a matter of fact, thoughtful rationalization for photoswitching processes is highly desired to further improve the efficiencies of DTEs. Considerable efforts have been developed worldwide to explore the excited state topologies of DTEs (or DAEs) via advanced optical spectroscopies and quantum chemical calculations. ${ }^{13}$

In recent years, we have undertaken several studies to thoughtfully investigate the photoswitching processes of different series of bridged DAEs ${ }^{14}$ or DTEs molecules, ${ }^{13 e, 14-15}$ combining ultrafast spectroscopies, chemometrics data treatment and (TD)-DFT calculations. Indeed, by blocking the molecule in a given conformation, the comparison of bridged $v$ s free analogs allows to distinguish the photochemistry of the AP conformer from the photophysics of $\mathrm{P}$ one (AP and P conformers are characterized by a rapid interconversion in the ground state and present similar absorption spectra). By this way, we have reported in 2010 two photocyclization pathways for cyano-substituted DAEs, ${ }^{14}$ results confirmed recently by advanced ab-initio calculations. ${ }^{16}$ Similarly, the ultrafast excited state and reaction dynamics of a series of inverse bridged DTEs have been fully understood in solution ${ }^{17}$ and in the gas-phase. ${ }^{15 a}$ In particular, we were able to prove that the systems photocyclized directly from the Franck-Condon region ( 120 fs) and not from the first relaxed excited state. Finally in 2016, due to its primordial place in the literature, ${ }^{18}$ we have reinvestigated the normal dithienylethene 1,2-bis(2,4-dimethyl-5-phenyl-3-thienyl)perfluorocyclopentene called later DTE together with its bridged analog ${ }^{19}$ called DTE- $m_{5}$ (DTE with a polyether bridged substituted at the meta position of the terminal phenyl rings). At first glance, DTE- $m_{5}$ was thought to block the molecule in the AP ideal conformation. Instead, we discovered that UV photoexcitation of ground state DTE- $m_{5}$ molecules gave birth to two triplet states, ${ }^{3} \mathrm{P}$ and ${ }^{3} \mathrm{AP}$ with distinct intersystem crossing (ISC) and relaxation process characteristic times. Furthermore, we found that the structural constraint opened up a new 
photocyclization pathway via ${ }^{3} \mathrm{AP}$ at about $10 \%$ extent. Because triplet species of DAEs have been more and more investigated recently, ${ }^{20}$ we decided to examine the photoreactivity-structure relationship for a complete series of bridged DTEs consisting of the parent molecule with an additional polyether chain of different length substituted at the meta $\left(D T E-m_{4}, D T E-m_{5}, D T E-m_{6}\right)$ or the ortho $\left(\right.$ DTE- $0_{5}$, DTE- $\left.o_{6}\right)$ positions with respect to the phenyl rings. Still combining femtosecond/nanosecond absorption spectroscopy, DFT calculations, and NMR techniques, we will evidence, for the first time, a triplet state interconversion process ${ }^{3} \mathbf{A P} \leftrightarrow{ }^{3} \mathbf{P}$. In addition, we will show the large dependency of the triplet photocyclization pathway yield to the length of the polyether chain.

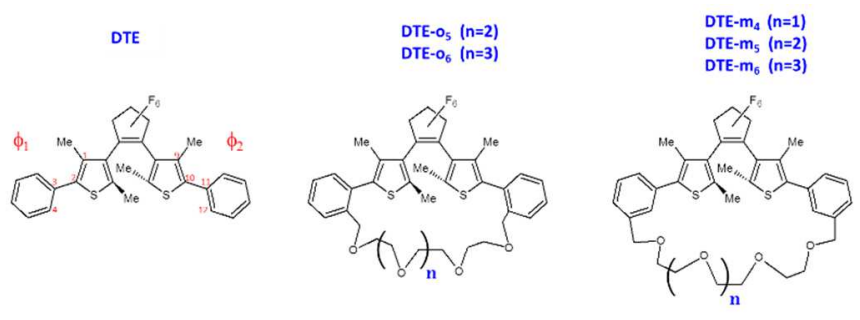

Scheme 1: Normal DTE, DTE- $\mathrm{o}_{x}$ and and DTE- $\mathrm{m}_{\mathrm{x}}$ bridged series. $\phi 1$ and $\phi 2$ are the dihedral angles between thiophene and phenyl rings.

\section{EXPERIMENTAL AND THEORETICAL METHODS}

Stationnary techniques.

All bridged DTEs were synthesized by Takeshita et al..$^{21}$ and the preparations are detailed in the previous work concerning DTE- $\mathrm{m}_{5} \cdot{ }^{19}$ Chloroform $\left(\mathrm{CHCl}_{3}\right)$ solvent (spectroscopic grade, Sigma-Aldrich) was used as received. The steady state absorption spectra were measured with a CARY 100 bio absorption spectrometer. ${ }^{1} \mathrm{H}-\mathrm{NMR}$ spectra in $\mathrm{CDCl}_{3}$, to determine AP/P ratio, were recorded on Bruker Avance-300 (300 MHz). The photocyclization and photoreversion yields have already been published for DTE ${ }^{22}$ and were determined in this work for all the molecules according to usual procedure. ${ }^{21}$

\section{Transient absorption techniques.}

Our nanosecond transient absorption spectroscopy setup has been described elsewhere. ${ }^{23}$ Briefly, a third harmonic pulse $(355 \mathrm{~nm})$ of a $\mathrm{Nd}$ :YAG laser with ca. $1 \mathrm{~mJ}$ output energy and $5 \mathrm{~ns}$ pulse width was used as excitation light and a pulsed Xe lamp was utilized as probe light. Transient absorption spectra were obtained from the transient absorption decays recorded at various wavelengths by sampling the absorbance changes for different given delay-times. ${ }^{19}$

Femtosecond time-resolved experiments were performed using a pump-probe spectrometer ${ }^{24}$ based on Ti:sapphire laser system (Coherent Mira-900-D oscillator and Libra-S regenerative amplifier) delivering $800 \mathrm{~nm}, 1 \mathrm{~mJ}$ and $90 \mathrm{fs}$ pulses with a repetition rate of $1 \mathrm{kHz}$. The pump pulses tuned at $320 \mathrm{~nm}$ were generated by frequency quadrupling the output of a Quantronix Palitra OPA pumped at $800 \mathrm{~nm}$ and the energy at the sample was about $2 \mu \mathrm{J}\left(0.2 \mathrm{~mJ} \mathrm{~cm}^{-2}\right)$. Note that, we choose to excite the molecule far from the maximum of absorption localized near $270 \mathrm{~nm}$ to avoid short-time 2-photon absorption signal coming from the solvent. The probe pulses were obtained by focusing $1 \mu \mathrm{J}, 800 \mathrm{~nm}$ pulses into a $1 \mathrm{~mm}$ thick $\mathrm{CaF}_{2}$ plate to generate a white light continuum. The pump-probe polarization configuration was set at the magic angle $\left(54.7^{\circ}\right)$. Transient absorbance was obtained by comparing signal and reference spectra with and without pump pulses for different delay-times. The delay-time between the pump and probe was varied up to $0.5 \mathrm{~ns}$ using an optical delay line. Sample solutions $\left(\sim 10^{-3}-10^{-5} \mathrm{~mol} \mathrm{dm}^{-3}, \mathrm{OD}=1\right.$ at the pump wavelength) were circulated in a cell equipped with $200 \mu \mathrm{m}$ thick $\mathrm{CaF}_{2}$ entrance window and having $2 \mathrm{~mm}$ optical path. During measurements, the solution was circulated and was irradiated by a CW Xe lamp visible light to prevent the accumulation of CF. In this configuration, for $320 \mathrm{~nm}$ excitation, the instrumental response function determined by fitting the stimulated Raman transient pic of acetonitrile was determined to be $180 \mathrm{fs}$. All the transient spectra presented in this paper are GVD corrected according to the typical extrapolation method ${ }^{25}$ (the temporal chirp over the white-light $350-800 \mathrm{~nm}$ range was about $400 \mathrm{fs}$ ). The characteristic times deduced from kinetics are obtained by fitting the data with the result of a multiexponential function convolved with a Gaussian pulse mimicking the pump-probe cross-correlation function (FWHM: $180 \mathrm{fs}$ ).

\section{Theoretical Calculations}

All the calculations have been performed using the Gaussian 09 package $^{26}$ within the Density Functional Theory (DFT) and TimeDependent (TD-DFT) frameworks, to model the ground-state (GS) and excited state (ES) properties, respectively.

In the course of the GS and ES geometry optimizations, we used the $\omega B 97 X D$ range-separated hybrid (RSH) functional ${ }^{27}$ combined with the 6-31G (d) atomic basis set. Contrary to conventional hybrid functionals, RSHs are known to avoid inconsistencies for ES geometries and this computational strategy was successfully applied in a previous study to investigate the structural properties of DTEs. ${ }^{19}$ All the geometry optimizations have been carried out in $\mathrm{CHCl}_{3}$, applying the Polarizable Continuum Model (PCM) ${ }^{28}$ to quantify the impact of the environment. Both the GS and ES geometry optimizations have been carried out in the equilibrium limit using the linear-response (LR) PCM scheme. For the lowest triplet state exploration $\left(T_{1}\right)$, the unrestricted formalism was considered, and the spin-contamination was systematically checked.

The optical properties have been determined using vertical TD-DFT calculations computed by the LR-PCM scheme in its non-equilibrium limit. At that stage, we have used the CAM-B3LYP/6-311+G(2d,p) methodology. We have previously demonstrated that this computational scheme is able to reproduce accurately the absorption wavelength $\lambda_{\mathrm{abs}}^{\max }$ of bridged DTEs. ${ }^{19}$

\section{RESULTS AND DISCUSSION}

Influence of ortho and meta positions on the structure, the quantum yields, the torsion angle and the absorption spectra.

Fig. 1 shows the absorption spectra of OF and CF of DTE, DTE- $m_{x}$ and DTE- $\mathrm{O}_{x}$ respectively, in chloroform solution. All the theoretical and experimental photochromic parameters together with AP:P proportion (from NMR experiments) are listed in Table 1. As seen in Fig. 1, ortho linked polyether bridges affect more strongly the optical properties of the molecules compared to the meta analogs in the sense that both CF and OF species are concerned. Indeed, as seen in Table 1, for DTE- $m_{x}$ series, $\sim 2 \mathrm{~nm}$ and $\sim 15 \mathrm{~nm}$ bathochromic shifts (in comparison with DTE) are reported for the OF and CF respectively. In the meantime, for DTE- $\mathrm{O}_{\mathrm{x}}$ series, $\sim 25 \mathrm{~nm}$ hypsochromic shifts are reported for both species. Thus to stress efficient structural constraint to both AP and $P$ conformers, polyether bridge has to face the well-known flexibility of OF (ground state AP-P equilibrium). Because, molecular orbitals responsible for OF/CF absorption bands are localized on the photochromic core and delocalized on the phenyl rings, the large spectral shifts reported so far have to be correlated with the torsion angle between the thiophene and the phenyl ring planes (see $\phi_{1}$ and $\phi_{2}$ in scheme 1). Indeed, in the case of 1,2-bis(2-methyl-5 
Table 1: Calculated and experimental photochromic parameters of DTE, DTE- $m_{\times}$and DTE- $\mathrm{O}_{\mathrm{x}}$ series in c hloroform.

\begin{tabular}{|c|c|c|c|c|c|c|c|c|c|c|c|c|c|}
\hline & \multicolumn{8}{|c|}{ Calculated values } & \multicolumn{5}{|c|}{ Experimental values } \\
\hline & \multicolumn{3}{|c|}{$r_{c c}(\AA)$} & \multicolumn{2}{|c|}{$\begin{array}{l}\text { Average torsion } \\
\text { angle difference / } \\
\text { DTE }\left({ }^{\circ}\right)^{\text {a }}\end{array}$} & \multicolumn{3}{|c|}{$\begin{array}{c}\lambda_{\mathrm{abs}}^{\max } \\
(\mathbf{n m})\end{array}$} & \multicolumn{2}{|c|}{$\begin{array}{c}\lambda_{\text {abs }}^{\max } \\
(\mathbf{n m})\end{array}$} & \multicolumn{2}{|c|}{$\begin{array}{l}\text { Quantum } \\
\text { Yields }\end{array}$} & \multirow{2}{*}{$\begin{array}{r}\%^{d} \\
\text { AP P }\end{array}$} \\
\hline & AP & $\mathbf{P}$ & CF & AP P & CF & AP P & & CF & OF & CF & $\phi_{\text {cycl }}{ }^{b}$ & $\phi_{\text {rev }}{ }^{c}$ & \\
\hline DTE & 3.78 & 4.00 & 1.53 & 00 & 0 & 2662 & 267 & 527 & 273 & 575 & 0.46 & 0.015 & $48 \quad 52$ \\
\hline DTE-m $m_{4}$ & 3.70 & 3.92 & 1.53 & 81 & 11 & 2682 & 263 & 526 & 274 & 590 & 0.29 & 0.026 & 3565 \\
\hline DTE-ms & 3.88 & 3.95 & 1.53 & 79 & 9 & 2772 & 263 & 513 & 272 & 580 & 0.36 & 0.015 & 4258 \\
\hline DTE- $m_{6}$ & 4.22 & 4.09 & 1.53 & 89 & 8 & 2672 & 275 & 527 & 273 & 576 & 0.43 & 0.014 & 4456 \\
\hline DTE-O ${ }_{5}$ & 4.30 & 4.24 & 1.53 & 3756 & 80 & 2592 & 254 & 508 & 256 & 550 & 0.41 & 0.056 & 4852 \\
\hline DTE-06 & 5.36 & 4.17 & 1.53 & 1323 & 58 & 2472 & 248 & 490 & 257 & 550 & 0.37 & 0.055 & 4159 \\
\hline
\end{tabular}

${ }^{\mathrm{a}}\left(\left|\phi_{1}-\phi_{1}(D T E)\right|+\left|\phi_{2}-\phi_{2}(D T E)\right|\right) / 2$; values for torsional angles see Table S.1; ${ }^{\mathrm{b}} @ 313 \mathrm{~nm} ;{ }^{\mathrm{c}} @ 517$ $\mathrm{nm} ;{ }^{\mathrm{d}}$ from NMR experiment.

-(4-methoxy-phenyl)-3-thienyl)perfluorocyclopentene ${ }^{29}$ and in the case of a diarylethene bearing carboxyl groups at ortho, meta and para positions in the single-crystalline phase ${ }^{30}$, similar bathochromic shifts were explained by the increase of the torsion angle. To confirm this hypothesis, we have optimized the structure of the different DTE series (Fig. 2) within the DFT framework. The energy difference between TDDFT and experimental absorption wavelengths (Table 1) is smaller than $0.19 \mathrm{eV}$ which validates our computational scheme.

Thus, from the calculated values of the two torsion angles (see Table S.1), an average has been computed and compared with the value computed for the parent molecule DTE, for the AP, $P$ and $C F$ species. As shown by Table 1 , for the DTE- $m_{x}$ series, the moderate bathochromic shift $(0-15 \mathrm{~nm})$ is correlated to the small torsion compared to DTE $\left(<11^{\circ}\right)$ while for the DTE- $\mathrm{O}_{x}$ series, the stronger bathochromic shifts, $\sim 25 \mathrm{~nm}$ for OF and CF, arise from the larger modification of the torsional angles (between $13^{\circ}$ and $80^{\circ}$ ). Therefore, we can conclude that polyether bridges are more effective when substituted in ortho position compared to meta position inducing probably some drastic changes for excited states topologies.

Consequently, quantum yields for photoswitching processes are also directly affected by the structural constraints. First, concerning the photocyclization yield (see Table 1), polyether bridges seem to change significantly the AP-P balance compared to the unbridged analog DTE: along the serie $\left(D T E-m_{4}, m_{5}\right.$ and $\left.m_{6}\right)$ the rise of $P$ population $(+25 \%$, $+12 \%,+8 \%$ ) corroborates the decrease of the ring closing efficiency ( $-37 \%,-22 \%,-7 \%)$. Furthermore, DTE- $m_{4}$ is the only molecule to display an increase of photoreversion yield $(+73 \%)$ compared to DTE- $m_{5}$ and DTE- $m_{6}$. Both effects are probably related to the shorter length of polyether bridge that should affect the overall topological points; in other words, when the bridge is too long, it cannot affect the photochemistry of the molecule anylonger. For the DTE- $\mathrm{o}_{\mathrm{x}}$ series, the most important observation concerns the increase of the photoreversion yields from $\sim 0.15$ to $\sim 0.55$ concomitantly with the $\sim 25 \mathrm{~nm}$ hypsochromic shift of the CF spectra. This effect is probably related to a diminution of the well-known potential barrier standing between $\mathrm{CF}^{*}$ and $\mathrm{OF}^{*}$ excited states. Closer inspection of the optimized structures of the P, AP and CF conformers (see Fig. 2) shows that in the case of DTE-O $\mathrm{O}_{5}$ (see Fig. 2) and DTE-O $\mathrm{O}_{6}$ (see Fig. S.11), the distance between the reactive carbons $r_{c c}$ in Table 1 is much larger than in the other compounds. Probably, this distented conformation is responsible for the singularity distinguishing ortho and meta series. Following our previous paper ${ }^{19}$ dealing with DTE and DTE- $m_{5}$, an investigation of the photophysics of the $P$ conformer and photochemistry of the AP and CF conformers will allow to rationalize the differences between the different series.
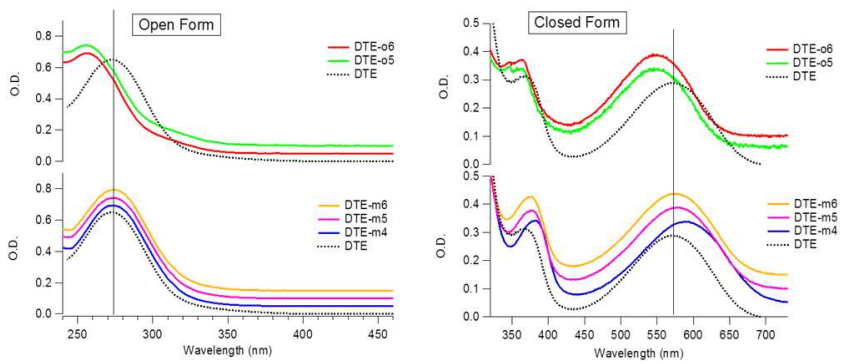

Fig. 1: Normalized Absorption spectra of the CF and OF for DTE, DTE- $m_{x}$ and DTE- $o_{x}$ molecules in chloroform. Offset of $0.05 \mathrm{OD}$ are applied for bridged molecules.
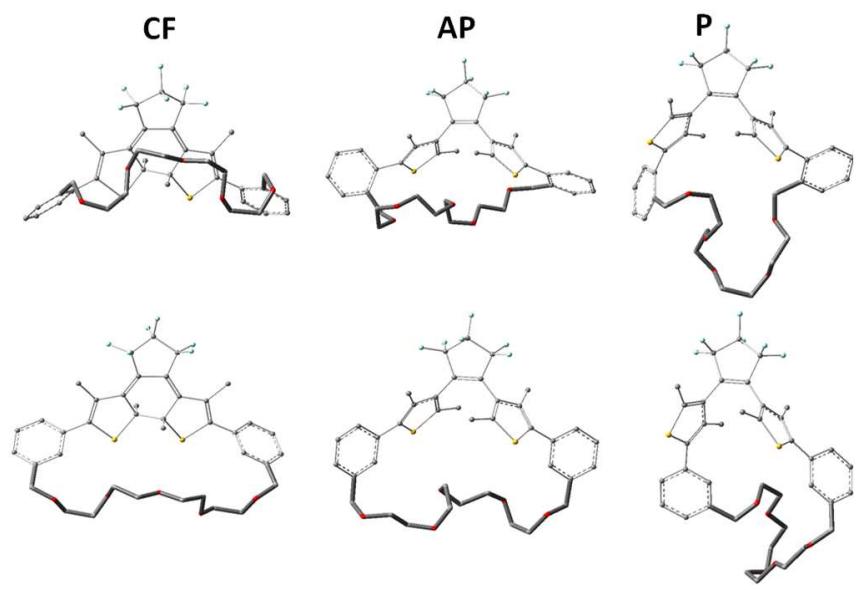

Fig. 2: DFT optimized structures at the $\omega B 97 X D / 6-31 G(d)$ level for the $C F$, $A P$ and $P$ of (top) DTE-O5, (down) DTE- $m_{5}$. The polyether chain is represented by tube model without hydrogen. All optimized structures are presented in Figure S.11 and Figure S.12.

\section{Photophysics of triplet states (Nanosecond regime)}

Nanosecond transient absorption spectra of DTE- $m_{5}$ recorded in chloroform, in the 350-700 nm spectral domain, for uncolored solution purged with $\mathrm{N}_{2}$ following $320 \mathrm{~nm}$ laser excitation are shown in Fig. 3 (top) while kinetics are shown in Fig. 3 (down). The overall molecules presented in this study display similar transient data (see Fig. S.4 and Fig. S.5) and precise assignations have been made in the past (see Fig. 3 and Fig. 4 of reference ${ }^{19}$ ). The kinetics at $440 \mathrm{~nm}$ can be fitted by a triexponential function (see characteristic times $\tau_{5}, \tau_{6}$ and $\tau_{7}$ in Table 2): the characteristic time $\tau_{5}$ and $\tau_{6}$ are attributed to the ${ }^{3} \mathrm{AP}$ and ${ }^{3} \mathrm{P}$ triplet states and $\tau_{7}$ (related with a so-call $X$ species) may describe the dynamics of polyether chain in the ground state. In addition, the $580 \mathrm{~nm}$ band corresponds to the CF signal. We determined the extent of $\mathrm{CF}$ coming from ${ }^{3} \mathrm{AP}$ using the diminution of $\triangle \mathrm{A}$ plateau value @ $580 \mathrm{~nm}$ (easily seen on kinetics) upon $\mathrm{O}_{2}$ bubbling inside the solution. The photocyclization pathway via the triplet state is more efficient for DTE- $0_{5}$, DTE- $m_{5}$ and DTE- $m_{4}(20 \%, 10 \%$ and $10 \%$ respectively) compared to DTE- $\mathrm{o}_{6}$ and DTE-m 6 ( $5 \%$ and $3.5 \%$ respectively). 

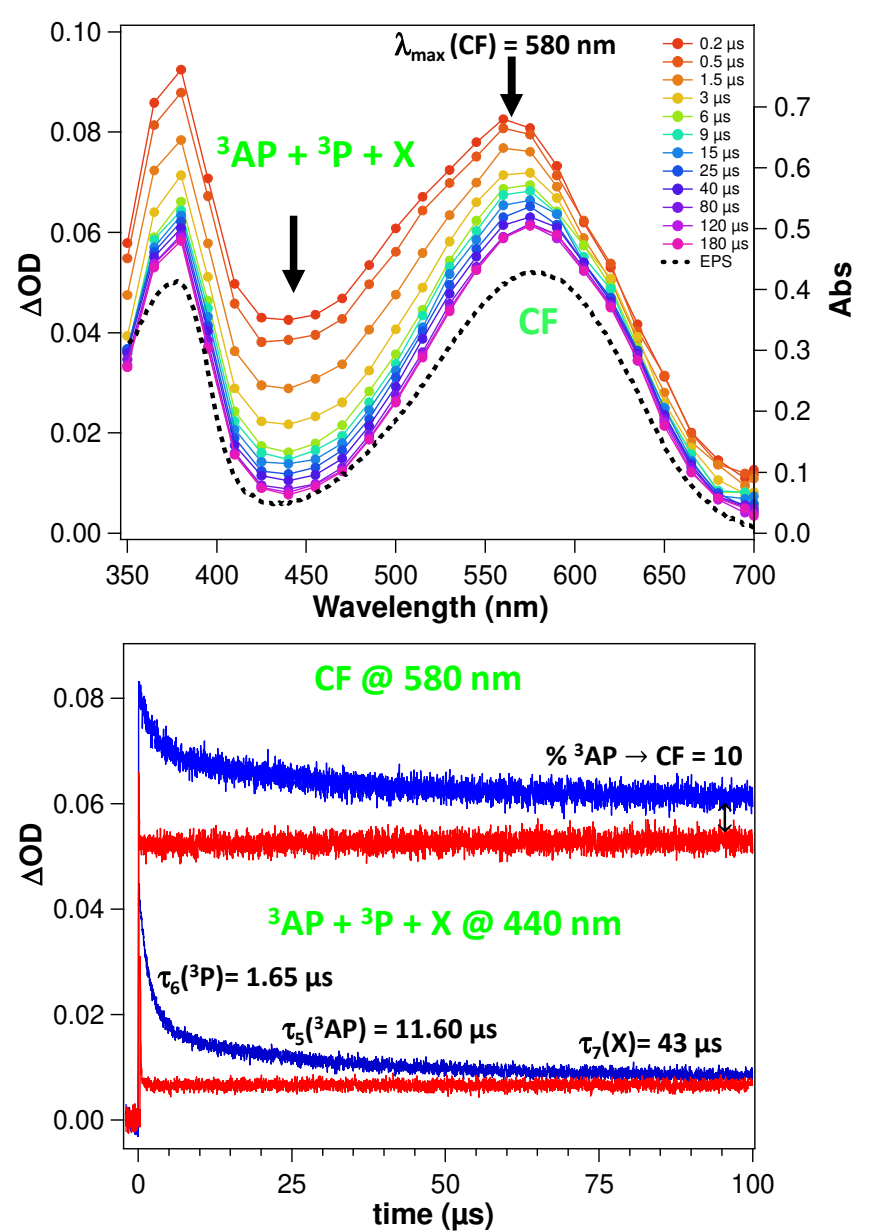

Fig. 3: (top) Microsecond time-resolved absorption spectra of DTE- $m_{5}$ in chloroform under $\mathrm{N}_{2}$ atmosphere after laser excitation at $320 \mathrm{~nm}$. (down) Kinetics recorded at $580 \mathrm{~nm}$ and $440 \mathrm{~nm}$ under $\mathrm{N}_{2}$ (bleu curve) and $\mathrm{O}_{2}$ saturated (red curve) atmosphere. The characteristic time constants derived from multiexponential fitting procedure are also given in the figure.

Table 2: Lifetimes deduced from multiexponentiel fitting of transient kinetics obtained from the laser-flash photolysis experiment for DTE, DTE- $m_{x}$ and DTE- $o_{x}$ molecules. \% of CF coming from triplet pathway (deduced from quenching experiment).

\begin{tabular}{|c|c|c|c|c|}
\hline & \multicolumn{3}{|c|}{ Lifetime ( $\mu \mathrm{s})$} & \multirow[t]{2}{*}{$\%^{3} \mathrm{AP} \rightarrow \mathrm{CF}$} \\
\hline & $\tau_{5}\left({ }^{3} \mathbf{A P}\right)$ & $\tau_{6}\left({ }^{3} \mathbf{P}\right)$ & $\tau_{7}(X)$ & \\
\hline DTE & $\begin{array}{c}25.5(4) \\
(20 \%)\end{array}$ & $\begin{array}{c}2.55(3) \\
(80 \%)\end{array}$ & $\cdots$ & 0 \\
\hline DTE-m 4 & $\begin{array}{c}12.5(5) \\
(17 \%)\end{array}$ & $\begin{array}{c}2.10(1) \\
(70 \%)\end{array}$ & $\begin{array}{l}38(2) \\
(13 \%)\end{array}$ & 10 \\
\hline DTE-m $m_{5}$ & $\begin{array}{c}11.6(3) \\
(55 \%)\end{array}$ & $\begin{array}{l}1.65(4) \\
(35 \%)\end{array}$ & $\begin{array}{l}43(1) \\
(10 \%)\end{array}$ & 10 \\
\hline DTE-m 6 & $\begin{array}{c}8(2) \\
(35 \%)\end{array}$ & $\begin{array}{c}1.70(2) \\
(40 \%)\end{array}$ & $\begin{array}{l}42(5) \\
(25 \%)\end{array}$ & 3.5 \\
\hline DTE-0.0 & $\begin{array}{c}6(1) \\
(25 \%)\end{array}$ & $\begin{array}{l}1.3(5) \\
(20 \%)\end{array}$ & $\begin{array}{l}52(2) \\
(55 \%)\end{array}$ & 20 \\
\hline DTE-O 6 & $\begin{array}{l}10(5) \\
(35 \%)\end{array}$ & $\begin{array}{l}1.5(1) \\
(28 \%) \\
\end{array}$ & $\begin{array}{l}47(2) \\
(37 \%) \\
\end{array}$ & 5 \\
\hline
\end{tabular}

To rationalize the photocyclization pathway via the triplet state ( $\left.{ }^{3} \mathrm{AP} \rightarrow \mathrm{CF}\right)$, additional DFT calculations have been performed including triplet state species. In the energy diagram of Fig. 4 , the energies of the ground and triplet states are given as a function of the distance between the reactive carbons $\left(r_{c c}\right)$. With those diagrams, one can compute the distance difference between $\mathrm{CF}$ and ${ }^{3} \mathrm{AP}$ topological points $\left(\Delta r_{c c}\right)$. We found that more efficient triplet photocyclization molecules have smaller $\Delta \mathrm{r}_{\mathrm{cc}}$ values between ${ }^{3} \mathrm{AP}$ and $\mathrm{CF}$ : for example, DTE-0 $5(2.09 \AA)$ and DTE- $m_{5}(1.60 \AA ̊)$ values are almost two times smaller compared to DTE- $\mathrm{o}_{6}(4.38 \AA$ ) $)$ and DTE-m 6 (2.53 $\AA$ ). Moreover, in the case of DTE- $\mathrm{O}_{6}$, the triplet state is oriented in the improper molecular coordinate direction ( $\Delta r_{c c}$ positive instead of negative) explaining the low quantum yield. Concerning, the lifetimes of ${ }^{3 \mathbf{p}}$ $(\sim 2 \mu \mathrm{s})$ and ${ }^{3} \mathrm{AP}(\sim 10 \mu \mathrm{s})$ reported on Table 2 , if the former is unaffected compared to DTE, the latter is divided by a factor going from $2\left(\mathrm{DTE}-\mathrm{m}_{4}\right)$ to $4\left(\mathrm{DTE}-\mathrm{O}_{5}\right)$. In this last case, the percentage of CF emanating from ${ }^{3} \mathrm{AP}$ is assessed to reach a maximum of $\sim 20 \%$. This experimental result is corroborated by the minimum energy gap between ${ }^{3} \mathrm{AP}$ and CF. Finally, it is worth to note that the extent of the $X$ species, assigned in our previous paper to be conformational relaxation of $\mathrm{CF}^{31}$ is enhanced for ortho series for which additional hydrogen bonding is reported between polyether bridge and photochromic core.

As an important conclusion from nanoseconde regime, if some specificities are noticed for the ortho series (enhancement of conformational relaxation), the main ${ }^{3} \mathrm{P}$ and ${ }^{3} \mathrm{AP}$ photophysics behavior remains similar for both series. We will see that in the femtosecond regime, this statement is no longer true.

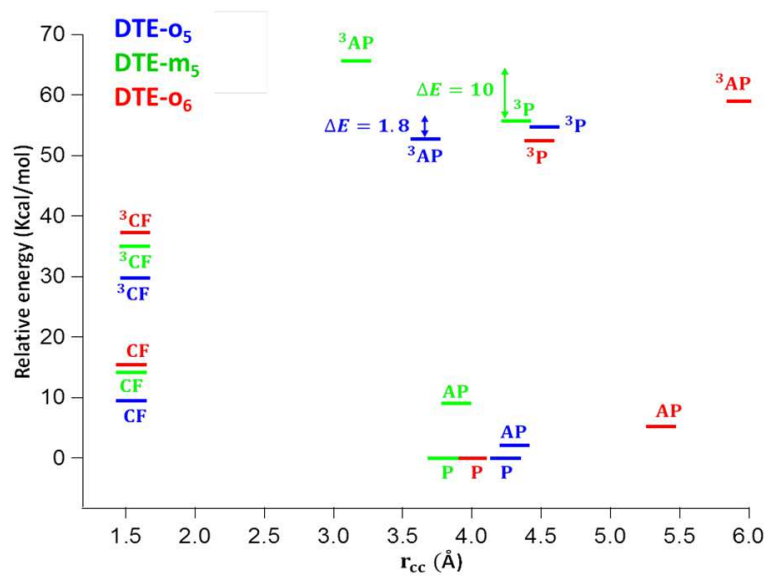

Fig. 4 Relative energies of the $S_{0}$ and $T_{1}$ states for the DTE- $\mathrm{O}_{5}$ (blue), DTE- $\mathrm{m}_{5}$ (green) and DTE- $\mathrm{O}_{6}$ structures (red) calculated at PCM $\left(\mathrm{CHCl}_{3}\right)-\omega \mathrm{B} 97 \mathrm{XD} / 6-31 \mathrm{G}(\mathrm{d})$. The energy of the most stable $\mathrm{S}_{0} \mathrm{P}$ conformer is considered as the energy reference. $\Delta \mathrm{E}$ represents the energy gap between the ${ }^{3} \mathrm{AP}$ and ${ }^{3} \mathrm{P}$.

Photocyclization of AP conformer (Femtosecond regime).

Transient absorption spectra of chloroform solutions of DTE- $0_{5}$ (right) and DTE-m5 (left) (for DTE- $0_{6}$, DTE- $\mathrm{m}_{4}$ and DTE-m $\mathrm{m}_{6}$ respectively see Fig. S.8) recorded in the $350-700 \mathrm{~nm}$ spectral range within four time-windows (-1-0.18, 0.24-0.9, 1-7 and 10-500 ps), following $320 \mathrm{~nm}$ excitation are shown in Fig. 5. Global fitting of transient signals with four-exponential $\left(D T E-m_{x}\right.$ ) or three-exponential (DTE- $o_{x}$ ) functions, convoluted with a Gaussian profile simulating the pump-probe correlation function are shown in supporting information (see Fig. S.7, Fig. S.9 and Fig. S.10). The characteristic times obtained for DTE, DTE$m_{x}$ and DTE- $o_{x}$ are gathered in Table 3. As a matter of fact, the interpretation of the data obtained for the complete series DTE- $m_{x}$ and DTE- $o_{x}\left(D T E-m_{5}\right.$ and DTE- $o_{5}$ presented in Fig. 5) strongly relies on the discussion published in our previous work for DTE and DTE- $\mathrm{m}_{5}{ }^{19}$ but some differences arise for the ortho- series.

For short delay-times (-1-0.18 ps), the transient absorption spectra exhibit two absorption bands peaking around $380 \mathrm{~nm}$ and $460 \mathrm{~nm}$, these two bands were attributed to the Excited States Absorption (ESA) of $S_{1}$ states within the Franck-Condon (FC) region of both $A P$ and $P$ conformers noticed respectively $\mathrm{S}_{1}^{\mathrm{FC}}(\mathrm{AP})$ and $\mathrm{S}_{1}^{\mathrm{FC}}(\mathrm{P})$. In the second panel (0.24-0.9 ps) for DTE- $m_{5}$, meanwhile the ESA signal of $P$ conformer seems to be constant, the band peaking at $380 \mathrm{~nm}$ 
decreases while a new band rises at $\sim 580 \mathrm{~nm}$ (max of CF absorbance) with a characteristic time $\tau_{1}$ of about $110-160$ fs for bridged DTE series (see Table 3). By referring to previous work, this characteristic time is unambiguously attributed to the ultrafast photocyclization via the $S_{1}$ FC state. ${ }^{16,31}$ Besides photocyclization, there is the parallel relaxation of the AP conformer from the FC region to the relaxed excited singlet state noticed $S_{1}^{\text {rel }}(A P)$. It is worth to note that $\tau_{1}$ is always higher compared to the unbridged analog which suggests that the polyether chain pulls apart the reactive carbons. Concerning DTE-o5, the photocyclization related spectral signature is extremely weak and the ESA band (near $420 \mathrm{~nm}$ ) of the $P$ conformer substantially decreases suggesting an Internal Conversion (IC) toward the ground state.

In the third panel (1-7 ps), substantial differences between meta and

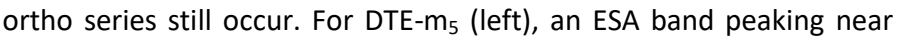
$460 \mathrm{~nm}$ decreases with a characteristic time $\tau_{2}=0.40 \mathrm{ps}$. This evolution is attributed to the relaxation of the $\mathrm{FC}$ state of the $\mathrm{P}$ conformer $\left(\mathrm{S}_{1}^{\mathrm{FC}}(\mathrm{P}) \rightarrow \mathrm{S}_{1}^{\mathrm{rel}}(\mathrm{P})\right)$. In the meantime, for DTE- $0_{5}$, such kind of evolution is missing in accordance with the IC of $\mathrm{P}$ conformers, previously reported, which is therefore the main relaxation pathway of $P$ excited state conformers.

Finally, for pump-probe delay-times higher than $10 \mathrm{ps}$ (panel 4), one can observe for DTE- $m_{5}$ a weak decrease of the $360 \mathrm{~nm}$ band attributed to $S_{1}^{\text {rel }}$ (AP) together with the decay of the $420 \mathrm{~nm}$ band attributed to $S_{1}^{\text {rel }}(\mathrm{P})$. Two characteristic times of $1.3 \mathrm{ps}$ and $70 \mathrm{ps}$ for DTE-m5 have been deduced from the fitting procedure; the shorter time is attributed to the Inter-System Crossing (ISC) of the AP conformer $\left(\mathrm{S}_{1}^{\text {rel }}(\mathrm{AP}) \rightarrow{ }^{3} \mathrm{AP}\right)$ while the longer one is ascribed to the ISC of the $\mathrm{P}$ conformer $\left(\mathrm{S}_{1}^{\text {rel }}(\mathrm{AP}) \rightarrow{ }^{3} \mathrm{AP}\right)$. In the meantime, as logically expected, a unique decay is reported for DTE- $\mathrm{O}_{5}$, which is related with the ISC of the AP conformers. In brief, for the meta- series, both ${ }^{3} \mathrm{AP}$ and ${ }^{3 \mathrm{P}}$ triplet states are produced while only the ${ }^{3} \mathrm{AP}$ is observed for the ortho- series.

Microsecond transient absorption data of DTE-O5 (see Table 2), indicated unambiguously the presence of the triplet state of both AP and $P$ conformers $\left(\tau_{1}=1.3 \mu \mathrm{s}\right.$ and $\left.\tau_{2}=6 \mu \mathrm{s}\right)$ which seems incoherent with the femtosecond absorption data conclusions. The only way to face this contradiction consists of relying on an interconversion at the triplet manifold for the ortho series, i.e. ${ }^{3} \mathrm{AP} \leftrightarrow{ }^{3} \mathrm{P}$. To confirm this assumption, theoretical calculations have been performed for DTE- $m_{x}$ and DTE- $\mathrm{O}_{x}$ molecules with optimized ${ }^{3} \mathrm{AP}$ and ${ }^{3} \mathrm{P}$ structures. As shown by Fig. 4 , in the case of DTE- $0_{5}$, the energy level difference between ${ }^{3} \mathrm{AP}$ and ${ }^{3} \mathrm{P}$ is 5 times lower $(\Delta \mathrm{E}=1.8 \mathrm{Kcal} / \mathrm{mol})$ than the one calculated for DTE- $m_{5}(\Delta E=10 \mathrm{Kcal} / \mathrm{mol})$. This feature indicates a possible lower energy barrier between the ${ }^{3} \mathrm{AP}$ and ${ }^{3} \mathrm{P}$ and the large feasibility of a rapid interconversion ${ }^{3} A P \leftrightarrow{ }^{3} P$ in the case of DTE- $\mathrm{O}_{\mathrm{x}}$ compared to DTE- $m_{x}$.
Table 3. Characteristic times deduced from the global fitting method applied to femtosecond transient absorption data for DTE, DTE-mx and DTE- $o_{x}$ open form UV excitation.

\begin{tabular}{lcccc}
\hline & $\boldsymbol{\tau}_{\mathbf{1}}(\boldsymbol{p} \boldsymbol{s})$ & $\boldsymbol{\tau}_{\mathbf{2}}(\boldsymbol{p} \boldsymbol{s})$ & $\boldsymbol{\tau}_{\mathbf{3}}(\boldsymbol{p s})$ & $\boldsymbol{\tau}_{\mathbf{4}}(\boldsymbol{p} \boldsymbol{s})$ \\
\hline DTE & $0.10(2)$ & $0.20(5)$ & $1.0(1)$ & $55(10)$ \\
DTE-m $_{4}$ & $0.11(3)$ & $0.21(2)$ & $40(6)$ & $140(30)$ \\
DTE-m $_{5}$ & $0.19(1)$ & $0.40(5)$ & $1.3(1)$ & $70(1)$ \\
DTE-m $_{6}$ & $0.15(7)$ & $0.23(2)$ & $3.3(5)$ & $43(7)$ \\
DTE-0 $_{5}$ & $0.16(1)$ & $0.32(1)$ & $1.2(1)$ & $\ldots$ \\
DTE-o $_{6}$ & $0.16(1)$ & $0.35(1)$ & $2.9(2)$ & $\ldots$ \\
\hline
\end{tabular}
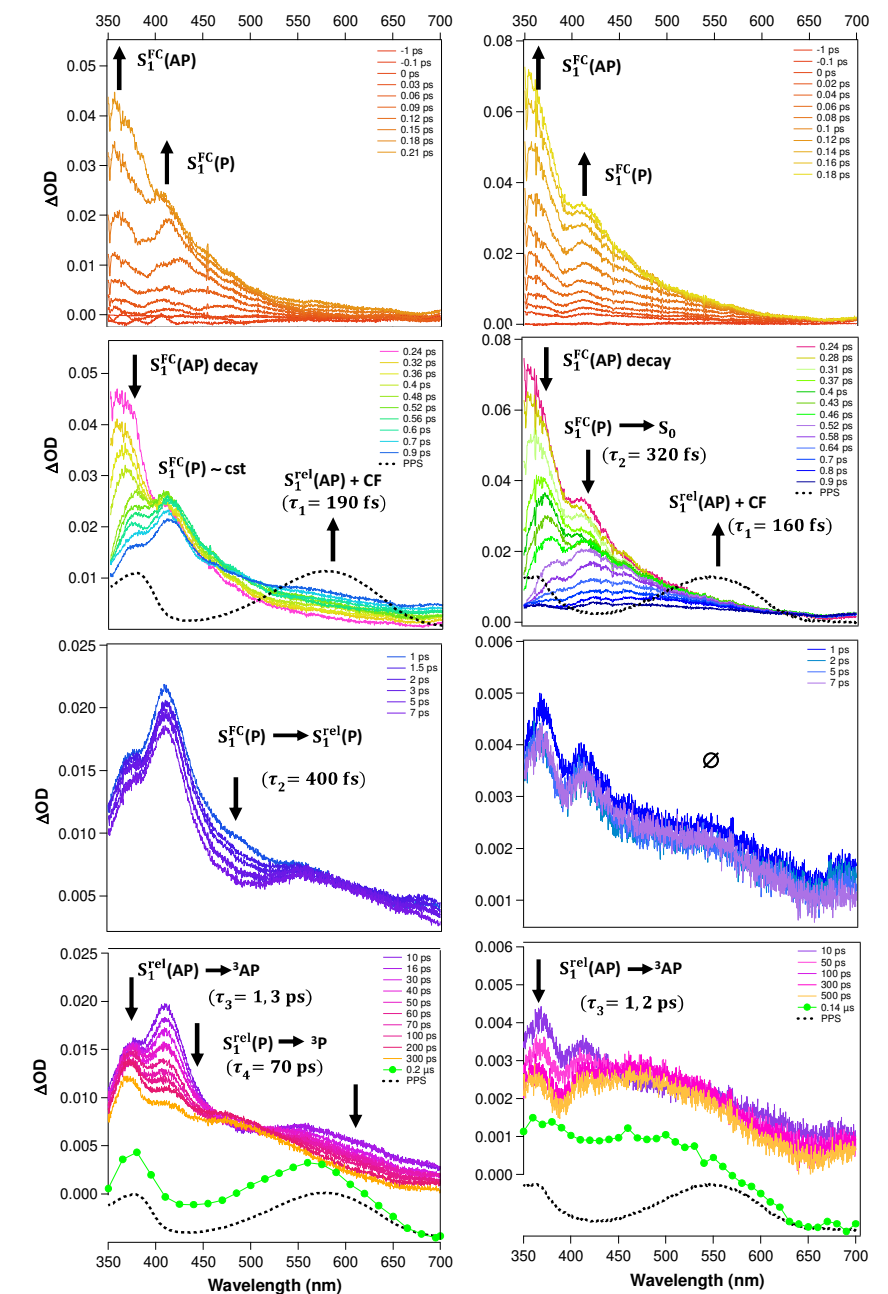

Fig. 5: Femto-picosecond time-resolved absorption spectra of DTE- $m_{5}$ (left) and DTE- $\mathrm{O}_{5}$ (right) in chloroform $(\sim 10 \mu \mathrm{M})$ using $320 \mathrm{~nm}$ excitation wavelength. The transient data are separated into four distinct temporal windows. All spectra are corrected from the GVD. The time constants derived from multiexponential fitting procedure convolved with a $180 \mathrm{fs}$ Gaussian instrumental response function are reported in the figure. 


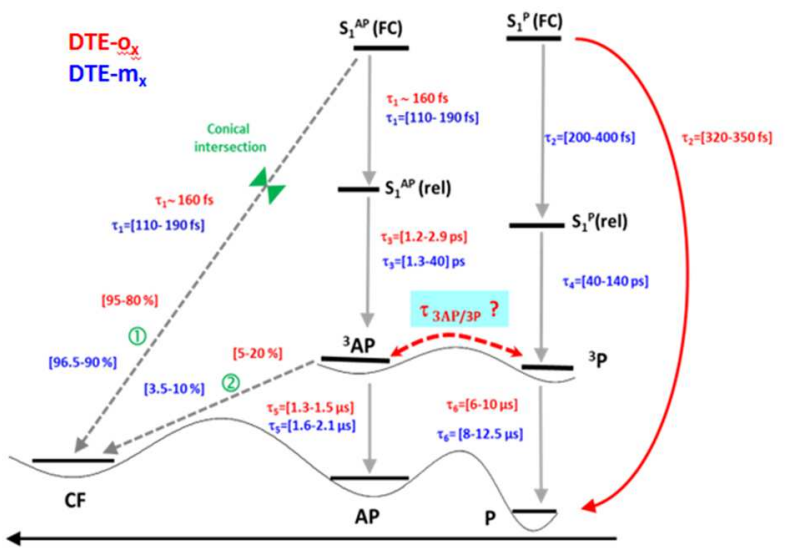

Fig. 6: Proposed photophysical and photochemical mechanisms including characteristic times for DTE- $\mathrm{O}_{\mathrm{x}}$ (red) and DTE- $\mathrm{m}_{\mathrm{x}}$ (blue) deduced from time resolved experiments. The molecular coordinate (horizontal axe) can be either carbone-carbone distance or dihedral angles difference.

\section{CONCLUSION}

Following our previous exploration of the DTE photoreactivity, distinguishing AP photocyclization from $P$ photophysics, we have investigated a series of bridged DTEs substituted with a polyether chain at the meta- and ortho- positions of the phenyl rings. For the DTE- $m_{x}$ molecules $(x=4-6)$, AP conformers within $\mathrm{FC}$ region photocyclize rapidly (110-190 fs) and decay within a parallel pathway to give rise to the relaxed $S_{1}$ state. The latter state, following an ISC mechanism, gives rise to a triplet state (1.3-40 ps) of short lifetime $(\sim 2 \mu \mathrm{s})$. In the meantime, the excited $P$ conformers undergo an ultrafast IC (200-400 fs) followed by an ISC (40-140 ps). Note that the effect of constraints is clearly noticed for DTE-m $m_{4}$ through faster photocyclization and much slower ISC process. Concerning the DTE- $o_{x}$ molecules $(x=4-6)$, the AP conformers photochemistry mimics the meta- analogs: photocyclization (160 fs) and ISC (1.2-3 ps) dominate the excited state electronic relaxation. Meanwhile, the $\mathrm{P}$ conformers undergo IC directly to the ground state without any production of $S_{1}$ relaxed state (and subsequent ISC). Despite this finding, the presence of a triplet state for the $\mathrm{P}$ conformer can be rationalized by a rapid interconversion at triplet state manifold. To the best of our knowledge, this is the first time that such excited state equilibrium is emphasized for DTE. The modifications of excited states topology being responsible for the new $\mathrm{P}$ conformers photophysics as well as the photocyclization via the triplet route, it appears relevant to undertake advanced multireference calculations to pave the way to the control of DTE excited states. Such theoretical efforts are presently undertaken in our laboratories.

\section{Acknowledgements}

Chevreul Institute (FR 2638), Ministère de l'Enseignement Supérieur et de la Recherche, Région Nord-Pas de Calais and FEDER are acknowledged for supporting and funding this work. Also, this work was granted access to the HPC resources of CINES and IDRIS under the allocation $\times 2016087623$ made by $\mathrm{GENCI}$ (Grand Equipement National de Calcul Intensif).

\section{Notes and references}

(a) Irie, M.; Fukaminato, T.; Sasaki, T.; Tamai, N.; Kawai, T. Nature 2002, 420, 759(b) Norsten, T. B.; Branda, N. R. Journal of the American Chemical Society 2001, 123, 1784(c) Tsivgoulis, G. M.; Lehn, J. M. Angewandte Chemie International Edition in English 1995, 34, 1119(d) Tian, H.; Chen, B.; Tu, H. Y.; Müllen, K. Advanced Materials 2002, 14, 918(e) Luo, Q.; Chen, B.; Wang, M.; Tian, H. Advanced Functional Materials 2003, 13, 233(f) Tian, H.; Qin, B.; Yao, R.; Zhao, X.; Yang, S. Advanced Materials 2003, 15, 2104. Matsuda, K.; Irie, M. Journal of the American Chemical Society 2000, 122, 8309.

(a) Gilat, S. L.; Kawai, S. H.; Lehn, J. M. Chemistry - A European Journal 1995, 1, 275(b) Peters, A.; Branda, N. R. Journal of the American Chemical Society 2003, 125, 3404(c) Browne, W. R.; De Jong, J. J. D.; Kudernac, T.; Walko, M.; Lucas, L. N.; Uchida, K.; Van Esch, J. H.; Feringa, B. L. Chemistry - A European Journal 2005, 11, 6414(d) Areephong, J.; Browne, W. R.; Katsonis, N.; Feringa, B. L. Chemical communications 2006, 3930.

(4) Bianchi, A.; Delgado-Pinar, E.; García-España, E.; Giorgi, C.; Pina, F. Coordination Chemistry Reviews 2014, 260, 156.

(5) (a) Irie, M.; Kobatake, S.; Horichi, M. Science 2001, 291, 1769(b) Kobatake, S.; Takami, S.; Muto, H.; Ishikawa, T.; Irie, M. Nature 2007, 446, 778(c) Uchida, K.; Sukata, S. I.; Matsuzawa, Y.; Akazawa, M.; De Jong, J. J. D.; Katsonis, N.; Kojima, Y.; Nakamura, S.; Areephong, J.; Meetsma, A.; Feringa, B. L. Chemical communications 2008, 326.

(6) Yao, X.; Li, T.; Wang, J.; Ma, X.; Tian, H. Advanced Optical Materials 2016, 4, 1322.

(7) (a) Tian, H.; Zhang, J. Photochromic materials: Preparation, properties and applications, 2016(b) Dürr, H.; Bouas-Laurent, $\mathrm{H}$. Photochromism: molecules and systems: molecules and systems; Gulf Professional Publishing, 2003(c) Fink, J. K. Polymeric Sensors and Actuators, 2012(d) Irie, M.; Yokoyama, Y.; Seki, T. New Frontiers in Photochromism; Springer: Japan, 2013.

(8) Irie, M. Chemical Reviews 2000, 100, 1685

(9) Irie, M.; Fulcaminato, T.; Matsuda, K.; Kobatake, S. Chemical Reviews 2014, 114, 12174.

(10) (a) Uchida, K.; Tsuchida, E.; Aoi, Y.; Nakamura, S.; Irie, M. Chemistry Letters 1999, 63(b) Morimitsu, K.; Kobatake, S.; Irie, M. Tetrahedron Letters 2004, 45, 1155.

(11) (a) Fukumoto, S.; Nakashima, T.; Kawai, T. European Journal of Organic Chemistry 2011, 5047(b) Fukumoto, S.; Nakashima, T.; Kawai, T. Angewandte ChemieInternational Edition 2011, 50, 1565(c) Li, W.; Jiao, C.; Li, X.; Xie, Y.; Nakatani, K.; Tian, H.; Zhu, W. Angewandte Chemie 2013, 126, 4691(d) Li, W.; Jiao, C.; Li, X.; Xie, Y.; Nakatani, K.; Tian, H.; Zhu, W. Angewandte Chemie International Edition 2014, 53, 4603.

(12) (a) Ishibashi, Y.; Miyasaka, H.; Kobatake, S.; Irie, M.; Yokoyama, Y. 2007 Pacific Rim Conference on Lasers and Electro-Optics, Vols 1-4 2007, 1364(b) Ishibashi, Y.; Mukaida, M.; Falkenstrom, M.; Miyasaka, H.; Kobatake, S.; Irie, M. Physical Chemistry Chemical Physics 2009, 11, 2640(c) Ishibashi, Y.; Okuno, K.; Ota, C.; Umesato, T.; Katayama, T.; Murakami, M.; Kobatake, S.; Irie, M.; Miyasaka, H. Photochem Photobiol Sci 2010, 9, 172. (a) Pontecorvo, E.; Ferrante, C.; Elles, C. G.; Scopigno, T. Journal of Physical Chemistry B 2014, 118, 6915(b) Ward, C. L.; Elles, C. G. Journal of Physical Chemistry Letters 2012, 
3, 2995(c) Boggio-Pasqua, M.; Ravaglia, M.; Bearpark, M. J.; Garavelli, M.; Robb, M. A. Journal of Physical Chemistry A 2003, 107, 11139(d) Boggio-Pasqua, M.; Bearpark, M. J.; Hunt, P. A.; Robb, M. A. Journal of the American Chemical Society 2002, 124, 1456(e) Perrier, A.; Aloise, S.; Olivucci, M.; Jacquemin, D. Journal of Physical Chemistry Letters 2013, 4, 2190.

(14) Aloïse, S. p.; Sliwa, M.; Pawlowska, Z.; Réhault, J.; Dubois, J.; Poizat, O.; Buntinx, G.; Perrier, A.; Maurel, F.; Yamaguchi, S. Journal of the American Chemical Society 2010, 132, 7379.

(15) (a) Lietard, A.; Piani, G.; Poisson, L.; Soep, B.; Mestdagh, J.M.; Aloise, S.; Perrier, A.; Jacquemin, D.; Takeshita, M. Physical Chemistry Chemical Physics 2014, 16, 22262(b) Aloise, S.; Ruan, Y.; Hamdi, I.; Buntinx, G.; Perrier, A.; Maurel, F.; Jacquemin, D.; Takeshita, M. Physical Chemistry Chemical Physics 2014, 16, 26762.

(16) Wang, Y.-T.; Gao, Y.-J.; Wang, Q.; Cui, G. J. Phys. Chem. A 2017, 121, 793.

(17) Aloise, S.; Sliwa, M.; Buntinx, G.; Delbaere, S.; Perrier, A.; Maurel, F.; Jacquemin, D.; Takeshita, M. Physical Chemistry Chemical Physics 2013, 15, 6226.

(18) (a) Yoshida, M.; Kamata, T.; National Institute of Advanced Industrial Science \& Technology, Japan . 2010(b) Tachibana, H.; National Institute of Advanced Industrial Science \& Technology AIST, Japan . 2012(c) Ichikawa, S.; Ogura, K.; Mitsubishi Pencil Company, Limited, Japan . 2015.

(19) Hamdi, I.; Buntinx, G.; Perrier, A.; Devos, O.; Jaïdane, N.; Delbaere, S.; Tiwari, A. K.; Dubois, J.; Takeshita, M.; Wada, Y.; Aloïse, S. Physical Chemistry Chemical Physics 2016, 18, 28091.

(20) (a) Indelli, M. T.; Carli, S.; Ghirotti, M.; Chiorboli, C.; Ravaglia, M.; Garavelli, M.; Scandola, F. Journal of the American Chemical Society 2008, 130, 7286(b) Murata, R.; Yago, T.; Wakasa, M. Bulletin of the Chemical Society of Japan 2011, 84, 1336(c) Murata, R.; Yago, T.; Wakasa, M. Journal of Physical Chemistry $A$ 2015, 119, 11138(d) Fukaminato, T.; Doi, T.; Tanaka, M.; Irie, M. Journal of Physical Chemistry C 2009, 113, 11623.

(21) Takeshita, M.; Tanaka, C.; Miyazaki, T.; Fukushima, Y.; Nagai, M. New Journal of Chemistry 2009, 33, 1433.

(22) Irie, M.; Sakemura, K.; Okinaka, M.; Uchida, K. Journal of Organic Chemistry 1995, 60, 8305.

(23) Buntinx, G.; Poizat, O.; Leygue, N. Journal of Physical Chemistry 1995, 99, 2343.

(24) (a) Buntinx, G.; Naskrecki, R.; Poizat, O. Journal of Physical Chemistry 1996, 100, 19380(b) Moine, B.; Rehault, J.; Aloise, S.; Micheau, J.-C.; Moustrou, C.; Samat, A.; Poizat, O.; Buntinx, G. Journal of Physical Chemistry A 2008, 112, 4719.

(25) (a) Nakayama, T.; Amijima, Y.; Ibuki, K.; Hamanoue, K. Review of Scientific Instruments 1997, 68, 4364(b) Ziolek, M.; Lorenc, M.; Naskrecki, R. Applied Physics B-Lasers and Optics 2001, 72, 843.

(26) Gaussian 09, R. A., Frisch, M. J.; Trucks, G. W.; Schlegel, H. B.; Scuseria, G. E.; Robb, M. A.; Cheeseman, J. R.; Scalmani, G.; Barone, V.; Mennucci, B.; Petersson, G. A.; Nakatsuji, H.; Caricato, M.; Li, X.; Hratchian, H. P.; Izmaylov, A. F.; Bloino, J.; Zheng, G.; Sonnenberg, J. L.; Hada, M.; Ehara, M.; Toyota, K.; Fukuda, R.; Hasegawa, J.; Ishida, M.; Nakajima, T.; Honda, Y.; Kitao, O.; Nakai, H.; Vreven, T.; Montgomery, Jr., J. A.; Peralta, J. E.; Ogliaro, F.; Bearpark, M.; Heyd, J. J.; Brothers, E.; Kudin, K. N.; Staroverov, V. N.;
Kobayashi, R.; Normand, J.; Raghavachari, K.; Rendell, A.; Burant, J. C.; Iyengar, S. S.; Tomasi, J.; Cossi, M.; Rega, N.; Millam, N. J.; Klene, M.; Knox, J. E.; Cross, J. B.; Bakken, V.; Adamo, C.; Jaramillo, J.; Gomperts, R.; Stratmann, R. E.; Yazyev, O.; Austin, A. J.; Cammi, R.; Pomelli, C.; Ochterski, J. W.; Martin, R. L.; Morokuma, K.; Zakrzewski, V. G.; Voth, G. A.; Salvador, P.; Dannenberg, J. J.; Dapprich, S.; Daniels, A. D.; Farkas, Ö.; Foresman, J. B.; Ortiz, J. V.; Cioslowski, J.; Fox, D. J. Gaussian, Inc., Wallingford CT 2009.

(27) (a) Chai, J. D.; Head-Gordon, M. Physical Chemistry Chemical Physics 2008, 10, 6615(b) Chai, J. D.; HeadGordon, M. Journal of Chemical Physics 2008, 128.

(28) Tomasi, J.; Mennucci, B.; Cammi, R. Chemical Reviews 2005, 105, 2999.

(29) Morimoto, M.; Kobatake, S.; Irie, M. Chemistry - $A$ European Journal 2003, 9, 621.

(30) Yamamoto, S.; Matsuda, K.; Irie, M. Chemistry - A European Journal 2003, 9, 4878.

(31) Hamdi, I.; Buntinx, G.; Poizat, O.; Perrier, A.; Le Bras, L.; Delbaere, S.; Barrau, S.; Louati, M.; Takeshita, M.; Tokushige, K.; Takao, M.; Aloïse, S. Journal of Physical Chemistry A 2018, 122, 3572. 